\title{
STABILITY-INDICATING REVERSE-PHASE HIGH-PERFORMANCE LIQUID CHROMATOGRAPHY METHOD FOR THE SIMULTANEOUS QUANTIFICATION OF APIGENIN AND LUTEOLIN FROM ACHILLEA MILLEFOLIUM LINN
}

\author{
GOMATHY SUBRAMANIAN ${ }^{1 *}$, S.N.MEYYANATHAN ${ }^{2}$, GOWRAMMA BYRAN ${ }^{1}$ \\ ${ }^{1}$ Department of Pharmaceutical Chemistry, JSS College of Pharmacy, JSS Academy of Higher Education and Research, Udhagamandalam. \\ Tamil Nadu, India. ${ }^{2}$ Department of Pharmaceutical Analysis, JSS College of Pharmacy, JSS Academy of Higher Education and Research, \\ Udhagamandalam, Tamil Nadu, India. Email: gomathys@jssuni.edu.in
}

Received: 11 January 2019, Revised and Accepted: 28 February 2019

ABSTRACT

Objective: A stability-indicating reverse-phase high-performance liquid chromatographic method was developed and validated for the analysis of apigenin and luteolin. The degradation behavior of apigenin and luteolin was investigated under different stress conditions as recommended by the International Conference on Harmonization (ICH).

Methods: In the present study, a reversed-phase high-performance liquid chromatography method was developed and the resolution of the plant constituents was successfully achieved using Hibar Lichrospher $\mathrm{C}_{8}$ column with ultraviolet detector at a wavelength of 269 nm. The mobile phase consisted of methanol and $0.5 \%$ trifluoroacetic acid $(80: 20 \mathrm{v} / \mathrm{v})$ at a flow rate of $1.0 \mathrm{ml} / \mathrm{min}$. Both apigenin and luteolin were subjected to various stress degradation studies such as oxidation, acid and alkaline hydrolysis, and photolytic degradation.

Results: The proposed method was found to be linear $(1-5 \mu \mathrm{g} / \mathrm{ml})$ with the linear correlation coefficient of $\mathrm{R}^{2}=0.99$. Although the degradation products of stressed conditions were not identified, the methods were able to detect the changes due to stress condition.

Conclusion: The method provides good sensitivity and excellent precision and reproducibility. Forced degradation studies on apigenin and luteolin give information about their storage and intrinsic stability conditions considering the advanced pharmaceutical aspects of formulations.

Keywords: Forced degradation, High-performance liquid chromatography, Stress studies, Validation, Apigenin and Luteolin.

(C) 2019 The Authors. Published by Innovare Academic Sciences Pvt Ltd. This is an open access article under the CC BY license (http://creativecommons. org/licenses/by/4. 0/) DOI: http://dx.doi.org/10.22159/ajpcr.2019.v12i4.31422

\section{INTRODUCTION}

Stability plays an important role in the herbal drug development process. It explains several factors that affect the expiration dating of herbal drug products including the chemical and physical stability during the preclinical formulation stages, process development, packaging development, and post-marketing life. The evaluation of the physicochemical stability of a given herbal product requires an understanding of the physical and chemical properties of the drug substance. Lack of drug substance or drug product stability may affect the purity, potency, and safety of the drug product [1]. Instability may also lead to the formation of toxic degradants. If instability of an herbal drug product leads to these unwelcome effects on patients, it could also lead to expensive costs to manufacturers as they attempt to discover the reasons for instability and methods of minimizing them.

By employing proper guidelines, it is possible to generate a sound stability data of herbal products and predict their shelf-life, which will help in improving global acceptability of herbal products [2]. The International Conference on Harmonization (ICH) guideline Q1A on stability testing of new drug substances suggests that the testing of those features which are susceptible to changes during storage and are likely to influence quality, safety, and efficacy must be done by validated stability-indicating methods. Stress testing should be carried out on a drug to establish its inherent stability characteristics and to support the suitability of the proposed analytical method. It also suggested that stress testing should include the effects of temperature, susceptibility across a wide range of $\mathrm{pH}$ values, as well as oxidative and photolytic conditions [3].

Forced degradation studies typically involve the exposure of representative sample of the herbal drug substance or herbal drug product to the relevant stress conditions of light, heat, humidity, acid/base hydrolysis, and oxidation [4,5]. The parent drug stability guidelines by the ICH (Q1AR) require that the stress testing of drug substance should include the effect of elevated temperature, humidity, light, oxidizing agents, as well as the susceptibility across a range of $\mathrm{pH}$ values [6]. These experiments play an important role in the herbal drug development process to facilitate: Stability-indicating method development, herbal drug formulation design, selection of storage conditions and packaging, and better understanding of the potential liabilities of the drug molecule chemistry.

Achillea millefolium L. (Yarrow) is a well-known medicinal plant, widely used in folk medicine against gastrointestinal disorders, lack of appetite [7]. The main active compounds in yarrow are flavonoids (apigenin [Fig. 1], luteolin [Fig. 2], rutin, and camperol) and essential oils (82 essential oil compounds have been identified). According to literature, the pharmacological effects are mainly due to the essential oil, phenolic compounds such as flavonoids and dicaffeoylquinic acids, and other sesquiterpene lactones. However, the phenolic compounds such as flavonoids and phenol carbonic acids are considered as one of the most important groups of pharmacologically active compounds present in Achillea species [8,9].

\section{MATERIALS AND METHODS}

Chemical and solvents

Apigenin and luteolin reference substances were procured from Natural Remedies, Bangalore. Methanol, trifluoroacetic acid, ammonium acetate, orthophosphoric acid, potassium dihydrogen phosphate, hydrochloric acid ( $\mathrm{HCl})$, hydrogen peroxide, perchloric acid, and sodium hydroxide were supplied by Qualigens Fine Chemicals and S.D. Fine chemicals. 


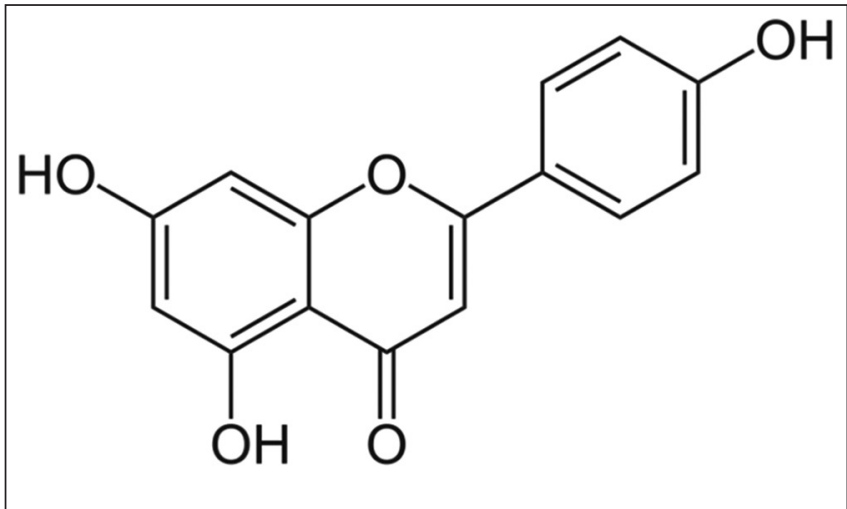

Fig. 1: Structure of apigenin

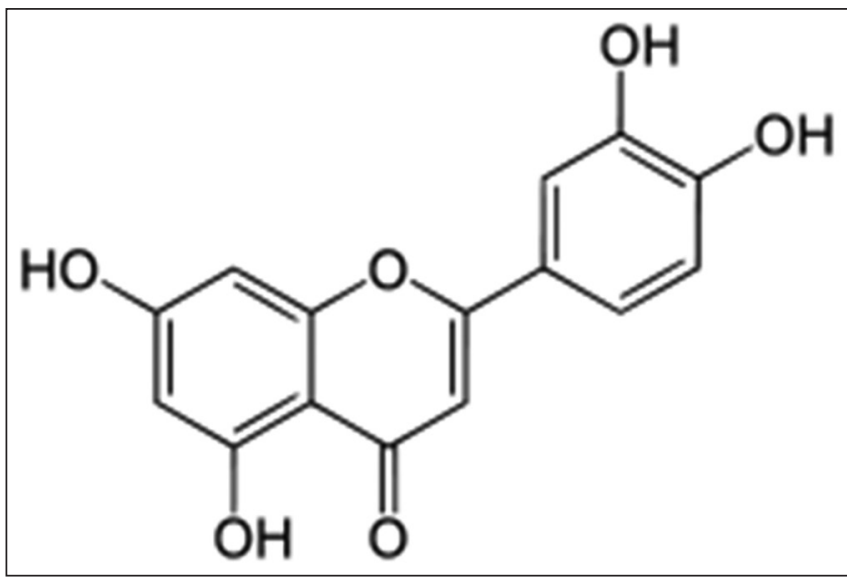

Fig. 2: Structure of luteolin

Water (high-performance liquid chromatography [HPLC] grade) was obtained from Milli-Q RO system. All the reagents and chemicals used were of HPLC and analytical grade.

\section{Instrumentation}

Chromatographic separation and quantitative determination were performed using a high-performance liquid chromatographic system, from Shimadzu (Kyoto, Japan) equipped with LC-10 AT-VP solvent data station delivery system, an SPD M10 A ultraviolet (UV) detector, and LC-2010 and an HT autosampler with loop volume of $100 \mu \mathrm{L}$, and the class VP data station was used. The stationary phase Hibar Lichrospher $\mathrm{C}_{8}$ column ( $150 \mathrm{~mm} \times 4.6 \mathrm{~mm}$ i.d., particle size $5 \mu$ ), UV detector at wavelength of $269 \mathrm{~nm}$ was used for the separation of the herbal constituents such as apigenin and luteolin.

\section{Preparation of standard solution}

The standard stock solution $(1 \mathrm{mg} / \mathrm{ml})$ of apigenin and luteolin was prepared using methanol. $10 \mathrm{mg}$ of each apigenin and luteolin was taken into $10 \mathrm{ml}$ volumetric flasks. To this, $5 \mathrm{ml}$ of methanol was added and sonicated for $10 \mathrm{~min}$ until a clear solution was obtained. The resulting solution was made up to $10 \mathrm{ml}$ with acetonitrile $[10,11]$. These stock solutions were stored in light-resistant containers. Aliquots of apigenin and luteolin $(1-5 \mu \mathrm{g} / \mathrm{ml})$ were prepared in the mobile phase for the analysis.

\section{Preparation of sample solution}

About $50 \mathrm{mg}$ of each extract was weighed and transferred into a $50 \mathrm{ml}$ volumetric flask. To this, $10 \mathrm{ml}$ of mobile phase solution was added and sonicated for $10 \mathrm{~min}$. The resulting solution was made up to $50 \mathrm{ml}$ with mobile phase and filtered through Whatman filter paper No. 42. Aliquots of the sample were prepared in the mobile phase. The standard and sample solutions were analyzed by the optimized chromatographic conditions and the chromatograms were recorded.

\section{Method validation}

The methods of analysis were validated as per the ICH guidelines [12,13] for parameters such as accuracy, linearity, precision, detection limit, quantitation limit, and robustness. The accuracy of the method was determined by calculating percentage recovery of apigenin and luteolin.

\section{Forced degradation studies of apigenin and luteolin}

To establish whether the analytical method and the assay were stability indicating, the selected plant constituents were stressed under various conditions to conduct forced degradation studies. As the constituents are freely soluble and stable in methanol, methanol was used as a cosolvent in all the forced degradation studies. The solutions were prepared by dissolving the herbal constituents in methanol, and further, the degradation was carried out in various degradation medias, namely $\mathrm{HCl}$ (acidic hydrolysis), sodium hydroxide (basic hydrolysis), hydrogen peroxide (oxidation), distilled water (neutral degradation), and UV light (photolysis). These degradation studies help to understand the inherent stability characteristic of the constituents in drug product and possible degradation products $[14,15]$.

\section{Standard stock solution}

About $10 \mathrm{mg}$ of each apigenin and luteolin was dissolved in $10 \mathrm{ml}$ methanol (1 $\mathrm{mg} / \mathrm{ml}$ solution). Depending on the extent of degradation observed, the studies were prolonged by certain variations in the concentrations of the degradation medium $[16,17]$. The studies were performed at room temperature, and in certain cases, it was extended to $24 \mathrm{~h}$ at room temperature.

\section{Acid degradation}

Degradation medium: $\mathrm{HCl}(1 \mathrm{~N})$

About $1 \mathrm{ml}$ of standard stock solution was taken into $10 \mathrm{ml}$ volumetric flask and volume was made up with $0.1 \mathrm{~N} \mathrm{HCl}$. The solution was kept at room temperature for $2 \mathrm{~h}$. The samples were analyzed after $2 \mathrm{~h}$. $1 \mathrm{ml}$ of sample was diluted to $10 \mathrm{ml}$ with mobile phase. The samples were injected and the chromatograms were recorded. $1 \mathrm{ml}$ aliquots of the samples were withdrawn at 1, 2, 4, 8, 12, and $24 \mathrm{~h}$. The samples were further diluted and analyzed by the optimized chromatographic conditions.

\section{Alkali degradation}

Degradation medium: Sodium hydroxide $(1 \mathrm{~N})$

About $1 \mathrm{ml}$ of standard stock solution was taken into $10 \mathrm{ml}$ volumetric flask and volume was made up with $0.1 \mathrm{~N}$ sodium hydroxide. The solution was kept at room temperature for $2 \mathrm{~h}$. The samples were analyzed after $2 \mathrm{~h} .1 \mathrm{ml}$ of sample was diluted to $10 \mathrm{ml}$ with mobile phase. The samples were injected and the chromatograms were recorded. $1 \mathrm{ml}$ aliquots of the samples were withdrawn at 1, 2, 4, 8, 12, and $24 \mathrm{~h}$.

\section{Neutral degradation}

About $1 \mathrm{ml}$ of standard stock solution was taken into $10 \mathrm{ml}$ volumetric flask and volume was made up with water. The solution was kept at room temperature for $2 \mathrm{~h}$. The samples were analyzed after $2 \mathrm{~h} .1 \mathrm{ml}$ of sample was diluted to $10 \mathrm{ml}$ with mobile phase. The samples were injected and the chromatograms were recorded. $1 \mathrm{ml}$ aliquots of the samples were withdrawn at $1,2,4,8,12$, and $24 \mathrm{~h}$.

\section{Oxidative degradation}

Degradation medium: Hydrogen peroxide (3\%)

About $1 \mathrm{ml}$ of standard stock solution was taken into $10 \mathrm{ml}$ volumetric flask and volume was made up with $3 \%$ hydrogen peroxide. The solution was kept at room temperature for $2 \mathrm{~h}$. The samples were analyzed after $2 \mathrm{~h} .1 \mathrm{ml}$ of sample was diluted to $10 \mathrm{ml}$ with mobile phase. The samples were injected and the chromatograms were recorded. $1 \mathrm{ml}$ aliquots of the samples were withdrawn at 1, 2, 4, 8, 12 , and $24 \mathrm{~h}$. 
Photolytic degradation

About $1 \mathrm{ml}$ of standard stock solution was taken into $10 \mathrm{ml}$ volumetric flask and volume was made up with water. The solution was exposed to UV light for $24 \mathrm{~h} .1 \mathrm{ml}$ aliquots of the samples were withdrawn at $1,2,4,8,12$, and $24 \mathrm{~h}$, diluted with mobile phase, and analyzed by the optimized chromatographic conditions.

\section{RESULTS AND DISCUSSION}

Optimization of chromatographic conditions

For the method development, a number of trials were carried out with different columns and mobile phases. The final optimized chromatographic conditions for the separation and quantification of apigenin and luteolin were obtained using an Hibar Lichrospher $\mathrm{C}_{8}$ column $(150 \mathrm{~mm} \times 4.6 \mathrm{~mm}$ i.d., particle size $5 \mu)$ and a mobile phase containing methanol and $0.5 \%$ trifluoroacetic acid $(80: 20 \% \mathrm{v} / \mathrm{v})$ for

Table 1: System suitability studies and validation for estimation of apigenin and luteolin by HPLC method

\begin{tabular}{llll}
\hline S. No & Parameters & Apigenin & Luteolin \\
\hline 1 & Linearity range & $1-5 \mu \mathrm{g} / \mathrm{ml}$ & $1-5 \mu \mathrm{g} / \mathrm{ml}$ \\
2 & Regression equation & $\mathrm{Y}=163491$ & $\mathrm{Y}=48642$ \\
& (Y=mx+c) & $\times-384$ & $\times-625$ \\
3 & Correlation coefficient & 0.992 & 0.997 \\
4 & Asymmetric factor & 1.0 & 1.1 \\
5 & LOD (ng/ml) & 26 & 48 \\
6 & LOQ (ng/ml) & 79 & 145 \\
\hline
\end{tabular}

HPLC: High-performance liquid chromatography the effective separation of these two constituents. Using $\mathrm{C}_{8}$ column, elution at a flow rate of $1 \mathrm{ml} / \mathrm{min}$ and detection wavelength of $269 \mathrm{~nm}$ with injection volume of $20 \mu \mathrm{l}$ afforded the best separation of these constituents. The chromatogram of the optimized method is shown in Fig. 3 and the system suitability parameters are shown in Table 1.

Forced degradation studies on apigenin and luteolin were carried out, and it was found that apigenin was more susceptible to acid (90.1\%) and neutral degradation (78.0\%), moderate to oxidation $(65.9 \%)$ and to lesser extent to basic degradation (46.1), and photodegradation $(30.2 \%)$. Luteolin was found to be more susceptible to basic degradation $(86.1 \%)$ and oxidation (63.8\%). Moderate degradation was found in acid degradation (35.4\%) and to lesser extent to light (28.8\%) and neutral degradation (12.1\%). The HPLC method developed for both the constituents resolves the degradation conditions, thus providing information on intrinsic stability of apigenin and luteolin. The forced degradation studies on apigenin and luteolin were performed, and it was concluded that these findings provide an insight and information about the storage and intrinsic stability conditions of apigenin and luteolin with respect to the advanced formulation aspects. The results of stress degradation studies of apigenin and luteolin by HPLC are summarized in Table 2 and acid degradation of apigenin and luteolin with $0.1 \mathrm{~N} \mathrm{HCl}$ is shown in Fig. 4.

\section{CONCLUSION}

The study concludes that apigenin is most liable to acid hydrolysis followed by neutral degradation and oxidation. It is moderately stable to basic degradation and photolysis. Luteolin is most liable to basic

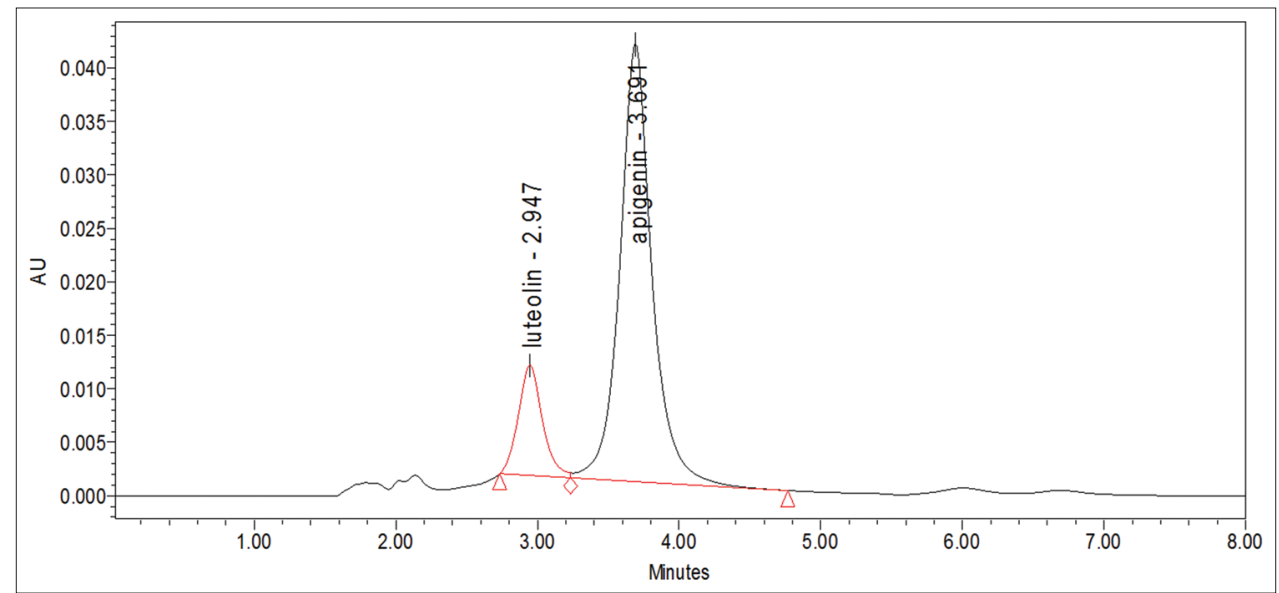

Fig. 3: Typical high-performance liquid chromatography

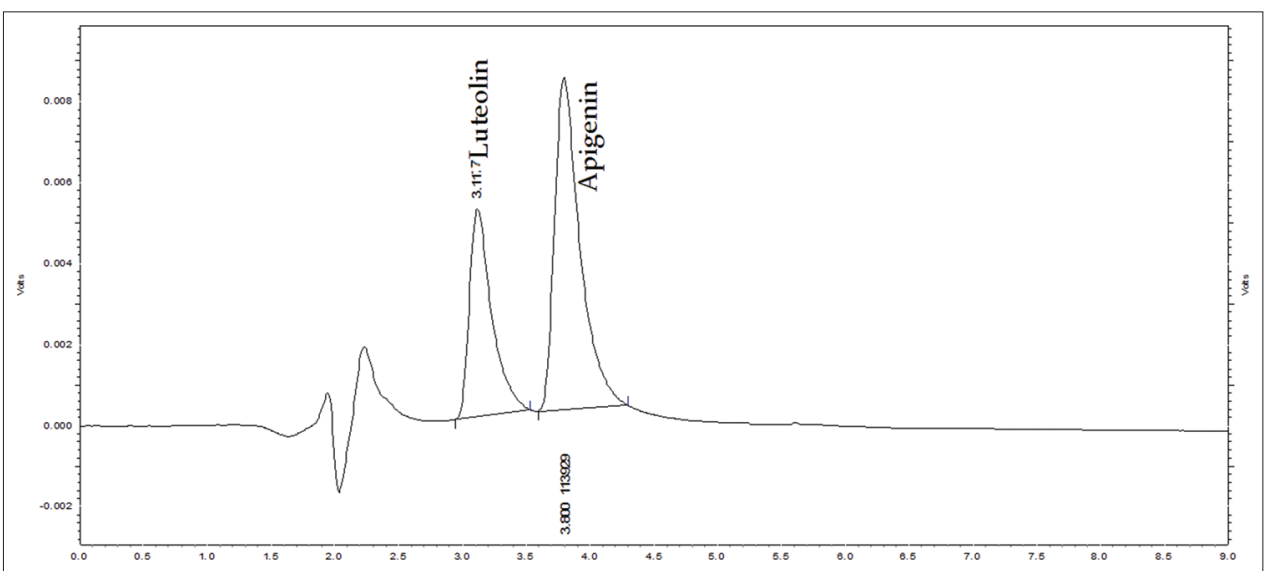

Fig. 4: Acid degradation of apigenin and luteolin with $1 \mathrm{~N}$ hydrochloric acid 
Table 2: Results of stress degradation studies of apigenin and luteolin by HPLC

\begin{tabular}{|c|c|c|c|c|c|c|c|c|c|c|c|}
\hline \multirow[t]{2}{*}{$\begin{array}{l}\text { S. } \\
\text { No }\end{array}$} & \multirow[t]{2}{*}{$\begin{array}{l}\text { Time } \\
\text { (h) }\end{array}$} & \multicolumn{2}{|c|}{$\begin{array}{l}\text { Acid hydrolysis \% } \\
\text { degradation } 1 \text { N HCl }\end{array}$} & \multicolumn{2}{|c|}{$\begin{array}{l}\text { Basic hydrolysis } \\
\% \text { degradation } 1 \mathrm{~N} \\
\mathrm{NaOH}\end{array}$} & \multicolumn{2}{|c|}{$\begin{array}{l}\text { Neutral degradation } \\
\% \text { degradation } \mathrm{H}_{2} \mathrm{O}_{2}\end{array}$} & \multicolumn{2}{|c|}{$\begin{array}{l}\text { Oxidative degradation } \\
\% \text { degradation } 3 \% \\
\mathrm{H}_{2} \mathrm{O}_{2}\end{array}$} & \multicolumn{2}{|c|}{$\begin{array}{l}\text { Photo degradation } \\
\% \text { degradation }\end{array}$} \\
\hline & & Apigenin & Luteolin & Apigenin & Luteolin & Apigenin & Luteolin & Apigenin & Luteolin & Apigenin & Luteolin \\
\hline 1 & 0 & 38.8 & 9.8 & 36.95 & 39.4 & 40.4 & 9.98 & 41.1 & 3.20 & 100 & 100 \\
\hline 2 & 2 & 48.1 & 11.2 & 38.8 & 49.1 & 43.8 & 10.1 & 42.1 & 5.60 & 100 & 100 \\
\hline 3 & 4 & 54.5 & 14.8 & 39.7 & 58.5 & 47.1 & 10.4 & 46.1 & 8.53 & 12.1 & 9.1 \\
\hline 4 & 8 & 78.9 & 25.4 & 40.5 & 66.9 & 56.5 & 11.7 & 48.9 & 17.0 & 18.8 & 16.7 \\
\hline 5 & 12 & 89.1 & 31 & 40.6 & 80.7 & 70.1 & 12.0 & 51.4 & 34.8 & 24.6 & 25.3 \\
\hline 6 & 24 & 90.1 & 35.4 & 46.1 & 86.1 & 78.0 & 12.1 & 65.9 & 63.8 & 30.2 & 28.8 \\
\hline
\end{tabular}

HPLC: High-performance liquid chromatography

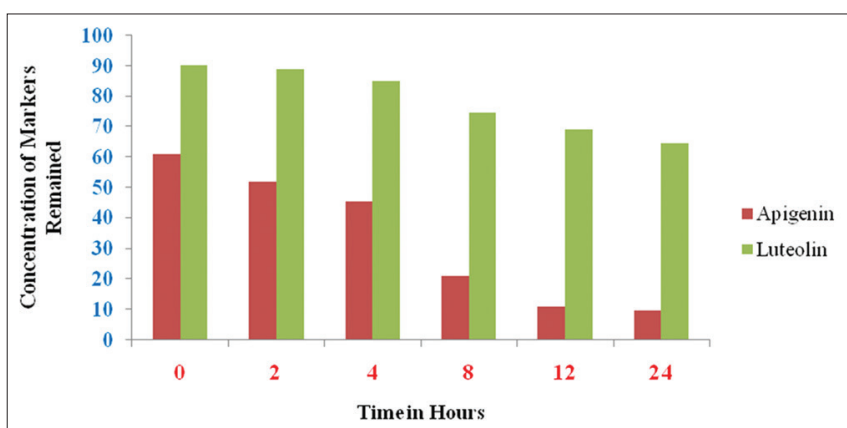

Fig. 5: The bar diagram of the acidic degradation of apigenin and luteolin

degradation followed by oxidation. It is stable to neutral degradation and photolytic degradation. The proposed method is sensitive, precise, accurate, and stability indicating. Thus, the proposed method can have its application in the determination of apigenin and luteolin in bulk drug, pharmaceutical formulation. The ICH guidelines have been followed throughout the study for method validation and stress studies, and thus, the proposed method has wide industrial applicability.

\section{ACKNOWLEDGMENTS}

The authors are grateful to His Holiness Jagadguru Sri Sri Shivarathri Deshikendra Mahaswamigalavaru of Sri Suttur Mutt, Mysore, for his blessings and the facilities provided to complete the research work successfully.

\section{AUTHORS' CONTRIBUTIONS}

We declare that the work was carried out by the authors named in this article. Dr. Gomathy Subramanian performed the laboratory work and wrote the introduction, discussion, methods and materials, and collected the data. Dr. S. N. Meyyanathan helped in conducting and designing of the study. Dr. B. Gowramma proofreads the manuscript.

\section{CONFLICTS OF INTEREST}

The authors declare that there are no conflicts of interest in relation to the publication of this paper.

\section{REFERENCES}

1. Folashade KO, Omoregie EH, Ochogu AP. Standardization of herbal medicines: A review. Int J Biodivers Conserv 2012;4:101-12.

2. Sachan AK, Kumar A. Stability testing of herbal products-A review. J Chem Pharm Res 2015;7:511-4.
3. Ahuja S, Alsante KM. Handbook of Isolation and Characterisation of Impurities in Pharmaceuticals. San Diego USA: Academic Press; 2003

4. Naidu KR, Kale UN, Shingare MS. Stability indicating RP-HPLC method for simultaneous determination of amlodipine and benazepril hydrochloride from their combination drug product. J Pharm Biomed Anal 2005;39:147-55

5. Blessy M, Patel RD, Prajapati PN, Agrawal YK. Development of forced degradation and stability indicating studies of drugs-A review. J Pharm Anal 2014;4:159-65.

6. International Federation of Pharmaceutical Manufacturers \& Associations. ICH, Q1A Stability Testing of New Drug Substances and Products: Proceedings of the International Conference on Harmonization. Geneva: International Federation of Pharmaceutical Manufacturers \& Associations; 2000.

7. Bimbiraite K, Ragazinskiene O, Maruska A, Kornysova O. Comparison of the chemical composition of four yarrow (Achillea millefolium L.) morphotypes. Biologija 2008;54:208-12.

8. Raote A, Jangid A, Tale R, Vaidya V. Liquid chromatography-Tandem mass spectrometric method for simultaneous determination of rutin and quercetin from leaves of Artocarpus lakoocha Roxb. Int J Pharm Bio Sci 2011;2:848-53

9. Devaraj VC, Krishna BG, Viswanatha GL. Simultaneous determination of quercetin, rutin and kaempferol in the leaf extracts of Moringa oleifera lam. And Raphinus sativus linn. By liquid chromatography-tandem mass spectrometry. Zhong Xi Yi Jie He Xue Bao 2011;9:1022-30.

10. Ashok Kumar BS, Lakshman K, Jayaveera KN, Vamshi Krishna N, Mnjunath M, Suresh MV. Estimation of rutin and quercetin in Amaranthus viridis Linn by HPLC. Asian J Exp Sci 2009;23:51-4

11. Shen H, Guo Q, Fang H, Wang Y, Jin M. Determination of quercetin, luteolin, apigenin and acacetin in flos Chrysanthemi indici by RPHPLC. Zhongguo Zhong Yao Za Zhi 2010;35:191-3.

12. Hamrapurkar P, Patil P, Desai M, Phale M, Pawar S. Stress degradation studies and development of a validated stability-indicating-assaymethod for determination of diacerein in presence of degradation products. Pharm Methods 2011;2:30-5.

13. Sarin YK. Problems in standardization of botanicals used by indigenous drug industry in India. Indian J Nat Prod 1993;9:12-7.

14. Rajendra BP, Tushar AD, Vijay RP. Stability indicating HPLC method for dapoxetine $\mathrm{HCl}$ in bulk and in formulation. Int $\mathrm{J}$ Pharm Pharm Sci 2014;6:687-90.

15. Kuna M, Dannana GS. Development and validation of stability indicating reverse-phase high performance liquid chromatography method for the simultaneous quantification of saquinavir, ritonavir and amprenavir. Asian J Pharm Clin Res 2018;11:390-6.

16. Alsante KM, Ando A, Brown R, Ensing J, Hatajik TD, Kong W, et al. The role of degradant profiling in active pharmaceutical ingredients and drug products. Adv Drug Deliv Rev 2007;59:29-37.

17. Reynolds DW, Facchine KL, Mullaney JF, Alsante KM, Hatajik TD, Motto MG. Available guidance and best practices for conducting forced degradation studies. Pharm Technol 2002;26:48-56. 